Вісник Дніпропетровського університету. Біологія. Екологія. -2010. - Вип. 18, т. 1. - С. 20-28.

Visnyk of Dnipropetrovsk University. Biology. Ecology. - 2010. - Vol. 18, N 1. - P. 20-28.

УДК 579.873.71:577.15

И. В. Жерносекова, Н. П. Черногор, А. А. Тымчук, А. И. Винников

Днепропетровский национальный университет им. Олеся Гончара

\title{
МЕТОДЫ ПЛАНИРОВАНИЯ ЭКСПЕРИМЕНТОВ ПРИ ОПТИМИЗАЦИИ ПИТАТЕЛЬНОЙ СРЕДЫ ДЛЯ СТРЕПТОМИЦЕТА
}

Оптимизирована питательная среда стрептомицета методом математического планирования эксперимента. Оптимизация ферментационной среды методом крутого восхождения совмещала в себе планирование полного факторного эксперимента (ПФЭ $2^{4}$ ) с методом движения по градиенту концентрации. Параметр оптимизации - активность стафилолитических ферментов, синтезируемых Streptomyces recifensis var. lyticus 2P-15. Активность стафилолитических ферментов на среде, оптимизированной методом крутого восхождения, составила 5589,4 ед./мл, что превышает активность ферментов на контрольной среде, полученной симплексным методом планирования эксперимента, на 69-86 \%.

I. В. Жерносєкова, Н. П. Чорногор, О. А. Тимчук, А. І. Вінніков

Дніпропетровський національний університет ім. Олеся Гончара

\section{МЕТОДИ ПЛАНУВАННЯ ЕКСПЕРИМЕНТІВ ПРИ ОПТИМІЗАЦІЇ ЖИВИЛЬНОГО СЕРЕДОВИЩА ДЛЯ СТРЕПТОМЩЕТУ}

Оптимізовано живильне середовище стрептоміцету методом математичного планування експериментів. Оптимізація ферментаційного середовища методом крутого сходження сполучала у собі планування за повним факторним експериментом (ПФЕ $2^{4}$ ) і метод руху за градіснтом концентрації. Параметр оптимізації - активність стафілолітичних ферментів, які синтезує Streptomyces recifensis var. lyticus 2P-15. Активність стафілолітичних ферментів на ферментаційному середовищі, оптимізованому методом крутого сходження, складала 5589,4 од./мл, що перевищує активність ферментів на контрольному середовищі, отриманому симплексним методом планування експерименту, на 69-86 \%.

\section{V. Zhernosekova, N. P. Chernogor, A. A. Tymchuk, A. I. Vinnikov Oles’ Honchar Dnipropetrovsk National University \\ METHODS OF EXPERIMENTS PLANNING BY OPTIMIZATION OF THE NUTRIENT MEDIUM FOR STREPTOMYCETE}

Nutritious medium for the streptomycete have been optimized by a method of experiment planning. Optimization of the fermentative medium by method combined planning of experiment (TFE $2^{4}$ complete factorial) with a method of concentration gradient motion. Activity of staphylolytic enzymes synthesized by Streptomyces recifensis var. lyticus $2 \mathrm{P}-15$ was studed as a parameter of the medium optimization. The enzymes activity averaged $5589.4 \mathrm{Un} / \mathrm{ml}$ in the medium optimized by a path-of-steepest-ascent method. That exceeds 69 $86 \%$ up on the enzymes activity in a control medium derived by a simplex method of experiment planning.

\section{Введение}

Разработка и последующее внедрение в практику современных технологий культивирования стрептомицетов, получения микробной биомассы и биологически активных веществ - продуктов их жизнедеятельности имеет большое практическое значение [10].

(С И. В. Жерносекова, Н. П. Черногор, А. А. Тымчук, А. И. Винников, 2010 
Оптимизация питательной среды является эффективным методом повышения биосинтетической активности продуцентов биологически активных веществ [4]. Оптимальный состав среды может быть определен двумя способами: методом эмпирического подбора и с использованием методов математического планирования эксперимента [1]. Применение методов активного эксперимента позволяет получать математические модели, описывающие свойства объектов исследований, при этом не возникает необходимости оценки процессов, протекающих внутри объекта. Получение математической модели обеспечивается четким выполнением алгоритма исследований и определением значений функции отклика объекта [5].

Традиционно состав питательной среды, оптимальной для выращивания продуцентов, определяется методом длительного эмпирического подбора, в ходе которого определяется качественный и количественный состав среды [8; 9; 11]. При оптимизации питательных сред для микроорганизмов все шире используют математический метод планирования экспериментов, что позволяет обоснованно подходить к конструированию питательных сред, делать их более экономичными [2].

Планирование эксперимента позволяет варьировать одновременно все факторы и получать количественные оценки как основных факторов, так и эффектов взаимодействия между ними, причем получаемые результаты характеризуются меньшей ошибкой, чем традиционные методы однофакторного исследования [3; 16; 17].

Учитывая большой практический интерес к литическим ферментам и необходимость разработки совершенной технологии их получения, представляется актуальным подбор состава и оптимизация ферментационной среды для Streptomyces recifensis var. lyticus - продуцента литических ферментов широкого спектра действия. С целью получения высокоактивных стафилолитических ферментов при культивировании стрептомицета проведена оптимизация состава ферментационной среды с использованием методов математического планирования экспериментов.

Поставленная цель является экстремальной задачей, в которой при большом числе независимых факторов (компонентов) питательной среды необходимо провести поиск той области факторного пространства, где синтез стафилолитических ферментов будет максимальным. Для решения поставленной задачи использованы регрессионные закономерности, полученные в ходе планирования эксперимента.

\section{Материал и методы исследований}

Объект исследований - рифампициноустойчивый штамм культуры S. recifensis var. lyticus 2435, выделенный из почвы, а в дальнейшем существенно модифицированный и улучшенный с помощью традиционных методов отбора штамма [15] и двух ступеней селекции [7]. Исследуемый штамм представляет собой наиболее перспективный вариант культуры продуцента, который синтезирует в жидкую ферментационную среду при глубинном культивировании комплекс литических ферментов, включающий эндопептидазы, гликозидазы, протеиназы, амилазы, ДНК-азы, при этом активность литических эндопептидаз составляла 1500 ед./мл [6; 14].

Культуру выращивали на агаризованной среде Гаузе 1 при температуре $-28^{\circ} \mathrm{C}$ в течение 12 суток. Состав посевной среды (г/л): соевая мука - 4,75, крахмал - 30,0, $\mathrm{NH}_{4} \mathrm{NO}_{3}-0,75, \mathrm{~K}_{2} \mathrm{HPO}_{4}-0,1, \mathrm{CaCO}_{3}-2,0, \mathrm{CaCl}_{2}-1,0$. Вода дистиллированная 1 литр; $p H$ среды - 8,0. Вегетативную культуру инокулировали в колбы объемом 500 мл, содержащие 50 мл стерильной ферментационной среды. Предыдущими исследованиями установлено, что продуцент лучше растет и проявляет наибольшую стафилолитическую активность на ферментационной среде следующего состава (Г/л): соевая 
мука - 6,0, глюкоза - 11,0, $\mathrm{NH}_{4} \mathrm{NO}_{3}-16,0, \mathrm{~K}_{2} \mathrm{HPO}_{4}-0,27, \mathrm{CaCO}_{3}-4,2, \mathrm{CaCl}_{2}-2,0$, $\mathrm{MnCl}_{2}-0,015, \mathrm{FeSO}_{4}-0,05, \mathrm{ZnSO}_{4}-2,0 \cdot 10^{-4}$. Литическую активность в отношении интактных клеток стафилококка определяли турбидиметрическим методом при 590 нм в кювете 0,5 см на КФК-2МП и выражали в ед./мл. За единицу бактериолитической активности принимали такое количество фермента, которое снижало оптическую плотность суспензии на 0,001 за 1 мин. при разведении фермента, способном лизировать взвесь клеток на 25-30 \% [18]. Для того, чтобы выяснить, являются ли оптимальными весовые соотношения компонентов, которые входят в состав этой среды, проведен полный факторный эксперимент (ПЭФ). Исследовано влияние на стафилолитическую активность исследуемого штамма четырех факторов среды культивирования: $X_{1}-$ $\mathrm{C}_{6} \mathrm{H}_{12} \mathrm{O}_{6}, \mathrm{X}_{2}-\mathrm{K}_{2} \mathrm{HPO}_{4}, \mathrm{X}_{3}-\mathrm{NH}_{4} \mathrm{NO}_{3}, \mathrm{X}_{4}-\mathrm{CaCO}_{3}$. Каждый фактор исследовали на двух уровнях (нижнем и верхнем).

\section{Результаты и их обсуждение}

В биотехнологическом процессе, организованном на основе использования высокопродуктивных штаммов - продуцентов, основное внимание должно уделяться не только созданию продуцента, его поддержанию, но и условиям культивирования. Для роста продуцента нужен жизнеспособный посевной материал, источники энергии и углерода, питательные вещества и соответствующие физико-химические условия культивирования [11]. Оптимизация условий культивирования может осуществляться на основе сочетания экспериментального и математического моделирования с проведением вычислительного эксперимента, который содержит важный этап - определение математической модели, то есть уравнения регрессии, характеризующего связь параметра оптимизации с основными факторами. Использование такой упрощенной модели позволяет быстрее сделать необходимые выводы о значимости тех или иных компонентов питательной среды, качественном и количественном ее составе.

Ранее при подборе состава ферментационных сред для синтеза стафилолитических ферментов $S$. recifensis var. lyticus был определен основной компонентный состав питательной среды, позволивший достичь уровня активности стафилолитических ферментов 1500 ед./мл. Оптимизация этой среды с использованием симплексного метода планирования эксперимента позволила при минимальных затратах (на двух ступенях использовано 8+10 вариантов сред) оптимизировать соотношение 10 компонентов питания, которые входили в состав исходной ферментативной среды. В варианте среды, разработанном симплексным методом, возросла концентрация $\mathrm{NH}_{4} \mathrm{NO}_{3}, \mathrm{~K}_{2} \mathrm{HPO}_{4}$, $\mathrm{CaCO}_{3}, \mathrm{CaCl}_{2}$ в 1,2-1,6 раза и существенно (в 9,4 раза) увеличено содержание глюкозы (с 0,07 до 0,66 \%). При этом активность штамма П-29 достигла 2000 ед./мл, а активность устойчивого к рифампицину штамма 2P-15 колебалась в пределах 3000 3300 ед./мл. Оптимизированная симплексным методом питательная среда позволила повысить активность штаммов по сравнению с исходным штаммом 2435 примерно в 2,0-2,3 раза [6]. Однако при использовании симплексного метода остается неизвестной математическая модель исследуемого процесса и невозможно оценить, как влияние отдельных факторов, так и их взаимодействий. Кроме того, процедура оптимизации слишком затянута во времени, так как построение следующего симплекса невозможно, пока не будет реализован предыдущий.

В связи с этим для оптимизации среды целесообразным, на наш взгляд, является использование метода ПФЭ, позволяющего поставить большое количество опытов, реализовать все возможные комбинации основных уровней независимых переменных факторов среды, установить оптимальные концентрации этих компонентов среды с 
учетом их совместного влияния на активность целевых ферментов, а также значительно быстрее, по сравнению с симплексным методом, найти и обосновать оптимальный состав среды.

Нами проведен эксперимент по оптимизации состава среды с использованием метода крутого восхождения, совмещающего в себе планирование эксперимента (ПФЭ) с методом движения по градиенту. Предварительными исследованиями определено, что на величину литической активности продуцента оказывают влияние четыре фактора среды: глюкоза, фосфорнокислый калий, аммоний азотнокислый и мел.

В планируемых экспериментах требовалось достигнуть оптимума стафилолитической активности ферментов при следующих ограничениях на основные компоненты среды: $X_{1} \leq 16,0, X_{2} \leq 0,8, X_{3} \leq 2,0, X_{4} \leq 2,5$ г/л.

В ходе факторного эксперимента со штаммом $2 \mathrm{P}-15$ проверены эти компоненты среды с целью определения среди них наиболее значимых для синтеза стафилолитических ферментов. В качестве контрольной среды использовали ферментационную среду, полученную симплексным методом планирования эксперимента.

Для построения математической модели реализован полный факторный эксперимент (ПФЭ $2^{4}$ ), при этом параметром оптимизации являлся уровень литической активности, а в качестве факторов варьирования взяты соответственно: $\mathrm{C}_{6} \mathrm{H}_{12} \mathrm{O}_{6}, \mathrm{~K}_{2} \mathrm{HPO}_{4}$, $\mathrm{NH}_{4} \mathrm{NO}_{3}, \mathrm{CaCO}_{3}$. Содержание остальных компонентов $\left(\mathrm{CaCl}_{2}, \mathrm{MnCl}_{2}, \mathrm{FeSO}_{4}, \mathrm{ZnSO}_{4}\right)$ зафиксировано на оптимальном (по результатам предыдущих экспериментов) уровне. При планировании по такой схеме реализовованы все возможные комбинации. Верхний и нижний уровни (табл. 1) устанавливали экспериментально предварительными однофакторными опытами. Исходя из значений этих параметров определяли центр плана и шаг варьирования. В безразмерной системе координат верхний уровень выражали +1 , нижний уровень -1 , координаты центра плана равны нулю.

Таблииа 1

Значения факторов в натуральных переменных, единицы варьирования (б г/л) и концентрации основных компонентов ферментационных сред

\begin{tabular}{|l|c|c|c|c|c|}
\hline $\begin{array}{c}\text { Компонент } \\
\text { среды }\end{array}$ & Фактор & $\begin{array}{c}\text { Основной } \\
\text { уровень (0), г/л }\end{array}$ & $\begin{array}{c}\text { Нижний } \\
\text { уровень }(-1), \text { г/л }\end{array}$ & $\begin{array}{c}\text { Верхний } \\
\text { уровень }(+1), \text { г/л }\end{array}$ & $\begin{array}{c}\text { Единицы } \\
\text { варьирования }(\sigma), \text { г/л }\end{array}$ \\
\hline $\mathrm{C}_{6} \mathrm{H}_{12} \mathrm{O}_{6}$ & $X_{1}$ & 12,0 & 10,0 & 14,0 & 2,0 \\
\hline $\mathrm{K}_{2} \mathrm{HPO}_{4}$ & $X_{2}$ & 0,3 & 0,2 & 0,4 & 0,1 \\
\hline $\mathrm{NH}_{4} \mathrm{NO}_{3}$ & $X_{3}$ & 1,5 & 1,0 & 2,0 & 0,5 \\
\hline $\mathrm{CaCO}_{3}$ & $X_{4}$ & 4,2 & 3,2 & 5,2 & 1,0 \\
\hline
\end{tabular}

Количество опытов определяли по формуле: $N=n^{k}$, где $k$ - число факторов, $n-$ количество уровней, то есть для двухуровневого полнофакторного эксперимента $N=2^{4}$. Таким образом, план ПФЭ $2^{4}$ позволил исследовать 16 вариантов питательных сред с одновременным варьированием всех четырех факторов на двух уровнях: верхнем $(+1)$ и нижнем (-1), среднее арифметическое между верхним и нижним уровнями представляет собой средний уровень.

Матрица планирования полного факторного эксперимента для четырех факторов представлена в таблице 2. В этом случае число возможных комбинаций из четырех факторов на двух уровнях равно $N=n^{k}=2^{4}=16$. Для получения расширенной матрицы планирования с фиктивной переменной, представленной в таблице 3 , вводится столбец с так называемой фиктивной переменной $x_{0}=1$. Нулевой фактор $\left(x_{0 i}\right)$ характеризует неучтенные факторы, влияющие на параметр оптимизации, и необходим для определения свободного члена уравнения регрессии $b_{0}$. Результаты эксперимента в каждой из серий испытаний представлены в столбцах $Y_{0}, Y_{1}, Y_{2}, \ldots, Y_{m}$ (табл. 2). 
Полный факторный эксперимент для четырех факторов

\begin{tabular}{|c|c|c|c|c|c|c|c|c|c|}
\hline \multirow{2}{*}{$\begin{array}{c}\text { Номер } \\
\text { опыта }\end{array}$} & \multicolumn{4}{|c|}{ Факторы в натуральном масштабе } & \multicolumn{4}{|c|}{ Факторы в безразмерной величине } & \multirow{2}{*}{$\begin{array}{c}\text { Выходной } \\
\text { параметр }\end{array}$} \\
\hline & $\overline{Z_{1}}$ & $Z_{2}$ & $Z_{3}$ & $Z_{4}$ & $X_{1}$ & $X_{2}$ & $X_{3}$ & $X_{4}$ & \\
\hline 1 & $Z_{1} \min$ & $Z_{2} \min$ & $Z_{3} \min$ & $Z_{4} \min$ & -1 & -1 & -1 & -1 & $\mathrm{Y}_{1}$ \\
\hline 2 & $Z_{1} \max$ & $Z_{2} \min$ & $Z_{3} \min$ & $Z_{4} \min$ & +1 & -1 & -1 & -1 & $\mathrm{Y}_{2}$ \\
\hline 3 & $Z_{1} \min$ & $Z_{2} \max$ & $Z_{3} \min$ & $Z_{4} \min$ & -1 & +1 & -1 & -1 & $\mathrm{Y}_{3}$ \\
\hline 4 & $Z_{1} \max$ & $Z_{2} \max$ & $Z_{3} \min$ & $Z_{4} \min$ & +1 & +1 & -1 & -1 & $\mathrm{Y}_{4}$ \\
\hline 5 & $Z_{1} \min$ & $Z_{2} \min$ & $Z_{3} \max$ & $Z_{4} \min$ & -1 & -1 & +1 & +1 & $\mathrm{Y}_{5}$ \\
\hline 6 & $Z_{I} \max$ & $Z_{2} \min$ & $Z_{3} \max$ & $Z_{4} \min$ & +1 & -1 & +1 & -1 & $\mathrm{Y}_{6}$ \\
\hline 7 & $Z_{1} \min$ & $Z_{2} \max$ & $Z_{3} \max$ & $Z_{4} \min$ & -1 & +1 & +1 & -1 & $\mathrm{Y}_{7}$ \\
\hline 8 & $Z_{I} \max$ & $Z_{2} \max$ & $Z_{3} \max$ & $Z_{4} \min$ & +1 & +1 & +1 & -1 & $\mathrm{Y}_{8}$ \\
\hline 9 & $Z_{1} \min$ & $Z_{2} \min$ & $Z_{3} \min$ & $Z_{4} \max$ & -1 & -1 & -1 & +1 & $\mathrm{Y}_{9}$ \\
\hline 10 & $Z_{I} \max$ & $Z_{2} \min$ & $Z_{3} \min$ & $Z_{4} \max$ & +1 & -1 & -1 & +1 & $Y_{10}$ \\
\hline 11 & $Z_{I} \min$ & $Z_{2} \max$ & $Z_{3} \min$ & $Z_{4} \max$ & -1 & +1 & -1 & +1 & $Y_{11}$ \\
\hline 12 & $Z_{I} \max$ & $Z_{2} \max$ & $Z_{3} \min$ & $Z_{4} \max$ & +1 & +1 & -1 & +1 & $Y_{12}$ \\
\hline 13 & $Z_{1} \min$ & $Z_{2} \min$ & $Z_{3} \max$ & $Z_{4} \max$ & -1 & -1 & +1 & +1 & $Y_{13}$ \\
\hline 14 & $Z_{I} \max$ & $Z_{2} \min$ & $Z_{3} \max$ & $Z_{4} \max$ & +1 & -1 & +1 & +1 & $Y_{14}$ \\
\hline 15 & $Z_{l} \min$ & $Z_{2} \max$ & $Z_{3} \max$ & $Z_{4} \max$ & -1 & +1 & +1 & +1 & $\mathrm{Y}_{15}$ \\
\hline 16 & $Z_{I} \max$ & $Z_{2} \max$ & $Z_{3} \max$ & $Z_{4} \max$ & +1 & +1 & +1 & +1 & $\mathrm{Y}_{16}$ \\
\hline
\end{tabular}

Проверка показала, что экспериментальные данные являются нормально распределенными и однородными. Приведенная в таблице 2 матрица обладает следующими свойствами: 1) свойство ортогональности (равенство нулю скалярных произведений всех векторов; 2) симметричность относительно центра; 3) условие нормировки; 4) ротатабельность, то есть точки в матрице планирования подбираются так, что точность предсказаний значений параметра оптимизации одинакова на равных расстояниях от центра эксперимента и не зависит от направления.

Коэффициенты уравнения регрессии определяются по методу наименьших квадратов, поэтому необходимо отметить, что экспериментальные данные должны быть однородными и нормально распределенными. Любой коэффициент уравнения регрессии определяется скалярным произведением столбца $Y$ на соответствующий столбец, отнесенным к числу опытов в матрице планирования $N$ :

$$
b_{i}=\frac{1}{N} \sum_{i=1}^{N} x_{i j} y_{i}
$$

где $b_{i}$ - коэффициент регрессии, $N$ - число возможных комбинаций; $x_{i j}-$ значение переменной в соответствующем столбце, $y_{i}$ - выход процесса, в данном случае активность стафилолитических ферментов.

Для определения коэффициентов взаимодействия необходимо расширить таблицу 2 дополнительными столбцами, учитывающими эффект двойного, тройного и четверного взаимодействия факторов (табл. 3). Эффекты взаимодействия определяли аналогично линейным эффектам [5]. В соответствии с данными таблицы 3 рассчитывали коэффициенты уравнения регрессии. Величина коэффициента регрессии $\left(b_{i}\right)$ характеризует вклад каждого фактора $\left(X_{i}\right)$ питательной среды в значения уровня стафилолитической активности $\left(Y_{i}\right)$ стрептомицета.

Полином первой степени при проведении планирования эксперимента ПФЭ $2^{4}$ имел вид $Y=b_{0}+b_{1} X_{1}+b_{2} X_{2}+b_{3} X_{3}-b_{4} X_{4}$, то есть

$$
Y=2499,9+410,9 X_{1}+451,6 X_{2}+409,7 X_{3}-156,5 X_{4} \text {. }
$$


Эффекты взаимодействия определяли аналогично линейным эффектам: коэффициенты парного взаимодействия равны соответственно: $b_{12}=42,31, b_{13}=-23,06$, $b_{23}=12,69, b_{123}=20,06, b_{14}=-8,19, b_{24}=3,44, b_{124}=19,56, b_{34}=69,31, b_{134}=21,44$, $b_{234}=-8,44, b_{1234}=-13,69$.

Полученное уравнение регрессии имело следующий вид:

$Y=2499,9+410,9 X_{1}+451,6 X_{2}+409,7 X_{3}-156,5 X_{4}+42,31 X_{1} X_{2}-23,06 X_{1} X_{3}+12,69 X_{2} X_{3}+$ $+20,06 X_{1} X_{2} X_{3}-8,19 X_{1} X_{4}+3,44 X_{2} X_{4}+19,56 X_{1} X_{2} X_{4}+69,31 X_{3} X_{4}+21,44 X_{1} X_{3} X_{4}-$ $-8,44 X_{2} X_{3} X_{4}-13,69 X_{1} X_{2} X_{3} X_{4}$.

Расширенная матрица планирования для ПФЭ $2^{4}$

Таблица 3

\begin{tabular}{|c|c|c|c|c|c|c|c|c|c|c|c|c|c|c|c|c|c|}
\hline $\begin{array}{c}\text { № } \\
\text { опы } \\
\text { та }\end{array}$ & $X_{0}$ & $X_{I}$ & $X_{2}$ & $X_{3}$ & $X 4$ & $X_{I}$ & $X_{1}$ & $X_{I}$ & $X_{2}$ & $X_{2}$ & $X_{3}$ & $X_{I}$ & $X_{1}$ & $X_{1}$ & $X_{2}$ & $X_{I}$ & \\
& & & & & $X_{2}$ & $X_{4}$ & $X_{3}$ & $X_{4}$ & $X_{4}$ & $X_{2}$ & $X_{2}$ & $X_{3}$ & $X_{3}$ & $X_{2}$ & $Y$ \\
$X_{3}$ & $X_{4}$ & $X_{4}$ & $X_{4}$ & \\
\hline 0 & 0 & 0 & 0 & 0 & 0 & 0 & 0 & 0 & 0 & 0 & 0 & 0 & 0 & 0 & 0 & 0 & 1833 \\
\hline 1 & 1 & -1 & -1 & -1 & -1 & 1 & 1 & 1 & 1 & 1 & 1 & -1 & -1 & -1 & -1 & 1 & 1256 \\
\hline 2 & 1 & 1 & -1 & -1 & -1 & -1 & -1 & -1 & 1 & 1 & 1 & 1 & 1 & 1 & -1 & -1 & 2462 \\
\hline 3 & 1 & -1 & 1 & -1 & -1 & -1 & 1 & 1 & -1 & -1 & 1 & 1 & 1 & -1 & 1 & -1 & 2359 \\
\hline 4 & 1 & 1 & 1 & -1 & -1 & 1 & -1 & -1 & -1 & -1 & 1 & -1 & -1 & 1 & 1 & 1 & 2924 \\
\hline 5 & 1 & -1 & -1 & 1 & -1 & 1 & -1 & 1 & -1 & 1 & -1 & 1 & -1 & 1 & 1 & -1 & 2367 \\
\hline 6 & 1 & 1 & -1 & 1 & -1 & -1 & 1 & -1 & -1 & 1 & -1 & -1 & 1 & -1 & 1 & 1 & 2862 \\
\hline 7 & 1 & -1 & 1 & 1 & -1 & -1 & -1 & 1 & 1 & -1 & -1 & -1 & 1 & 1 & -1 & 1 & 3051 \\
\hline 8 & 1 & 1 & 1 & 1 & -1 & 1 & 1 & -1 & 1 & -1 & -1 & 1 & -1 & -1 & -1 & -1 & 3971 \\
\hline 9 & 1 & -1 & -1 & -1 & 1 & 1 & 1 & -1 & 1 & -1 & -1 & -1 & 1 & 1 & 1 & -1 & 1119 \\
\hline 10 & 1 & 1 & -1 & -1 & 1 & -1 & -1 & 1 & 1 & -1 & -1 & 1 & -1 & -1 & 1 & 1 & 1958 \\
\hline 11 & 1 & -1 & 1 & -1 & 1 & -1 & 1 & -1 & -1 & 1 & -1 & 1 & -1 & 1 & -1 & 1 & 1891 \\
\hline 12 & 1 & 1 & 1 & -1 & 1 & 1 & -1 & 1 & -1 & 1 & -1 & -1 & 1 & -1 & -1 & -1 & 2753 \\
\hline 13 & 1 & -1 & -1 & 1 & 1 & 1 & -1 & -1 & -1 & -1 & 1 & 1 & 1 & -1 & -1 & 1 & 2137 \\
\hline 14 & 1 & 1 & -1 & 1 & 1 & -1 & 1 & 1 & -1 & -1 & 1 & -1 & -1 & 1 & -1 & -1 & 2546 \\
\hline 15 & 1 & -1 & 1 & 1 & 1 & -1 & -1 & -1 & 1 & 1 & 1 & -1 & -1 & -1 & 1 & -1 & 2532 \\
\hline 16 & 1 & 1 & 1 & 1 & 1 & 1 & 1 & 1 & 1 & 1 & 1 & 1 & 1 & 1 & 1 & 1 & 3811 \\
\hline
\end{tabular}

Полученные данные свидетельствуют о том, что концентрации глюкозы, $\mathrm{K}_{2} \mathrm{HPO}_{4}$ и $\mathrm{NH}_{4} \mathrm{NO}_{3}$ в питательной среде культивирования стрептомицета существенно влияют на активность литических ферментов. Увеличение относительно среднего уровня (вариант 0) содержания в среде факторов $X_{1}$ (глюкоза), $X_{2}\left(K_{2} H_{P O}\right)$ и $X_{3}$ $\left(\mathrm{NH}_{4} \mathrm{NO}_{3}\right)$ и снижение содержания фактора $\mathrm{X}_{4}\left(\mathrm{CaCO}_{3}\right)$ должно дать значимый положительный эффект. Увеличение глюкозы на 2 мг/мл, $\mathrm{K}_{2} \mathrm{HPO}_{4}$ - на 0,1 мг/мл, а $\mathrm{NH}_{4} \mathrm{NO}_{3}-$ на 0,5 мг/мл повышает активность стафилолитических ферментов соответственно на $410,9,451,6$ и 411,6 ед./мл, а увеличение $\mathrm{CaCO}_{3}$ на 1 мг/мл приводит к снижению активности на 156,5 ед./мл. Таким образом, эксперимент, в котором в серии различных вариантов ферментационной среды одновременно, с определенным шагом, будут снижаться концентрации «отрицательных» и увеличиваться концентрации «положительных» компонентов, должен привести к решению поставленной задачи - получению оптимальной по составу ферментационной среды.

Значимость коэффициентов регрессии проверяли по критерию Стьюдента. Дисперсия воспроизводимости коэффициентов регрессии составляла 768,30, ошибка дисперсии - 192,07. Коэффициенты регрессии считали отличными от нуля, если выполнялось следующее неравенство: $\left|b_{i}\right|>t_{0,05}(f) S\left\{b_{i}\right\}$, где $f$ - число степеней свободы, $t_{0,05}-$ критерий Стьюдента при 5 \% уровне значимости, который находится по таблице [12]. 
Полученные данные свидетельствуют о том, что следует признать значимыми коэффициенты $b_{1}, b_{2}$ и $b_{3}$ и включить их в модель, а коэффициенты $b_{4}, b_{12}, b_{13}, b_{23}, b_{12}$, $b_{14}, b_{24}, b_{124}, b_{34}, b_{134}, b_{234}, b_{1234}$ незначимы и их следует отбросить, не включая в искомую модель. На основании полученных данных математическая модель (уравнение регрессии), включающая только значимые коэффициенты, выглядит следующим образом:

$$
Y=2499,9+410,9 X_{1}+451,6 X_{2}+409,7 X_{3} \text {. }
$$

Проверку адекватности полученной модели проводили с использованием $F$-критерия Фишера. Вычисленное значение $F$ было меньше табличного $F_{0,05}$, что доказывает адекватность найденной модели.

На основании результатов проведенного ПФЭ можно предположить, что для дальнейшей оптимизации среды применение метода крутого восхождения будет эффективным, так как полученная линейная модель адекватна и не является резко асимметричной относительно коэффициентов.

На следующем этапе исследований расчет крутого восхождения проводили в такой последовательности.

1. Величину шага движения по градиенту концентраций факторов в среде рассчитывали по стандартной методике, исходя из значений коэффициентов регрессии. С этой целью переход к новому натуральному масштабу интервалов варьирования осуществляли с помощью формулы: $L_{i}=b_{i} \delta_{i}$, где $b$ - коэффициенты регрессии, $\delta_{i}$ - единицы варьирования. Рассчитано, что $L_{1}=821,8, L_{2}=45,16, L_{3}=54,85$. Абсолютная величина $\left|L_{\text {max }}\right|$ имеет наибольшее значение для глюкозы, следовательно, глюкоза является базовым фактором. Для остальных факторов коэффициенты рассчитывали по формуле:

$$
\gamma_{i}=\frac{L i}{|L \max |},
$$

где $\gamma_{i}$ - новые коэффициенты при значимых факторах. Рассчитанные коэффициенты составили для глюкозы, двузамещенного фосфата калия и нитрата аммония соответственно: $\gamma_{1}=1,0, \gamma_{2}=0,055, \gamma_{3}=0,067$.

2. Для базового фактора $\left(X_{l}\right)$ выбирали модуль шага движения по градиенту $\left(h_{\text {баз. }}\right)$. Шаг движения не должен превышать интервала варьирования по базовому фактору $h_{\text {баз. }}=\delta_{\text {баз. }}$. Поэтому, в нашем случае, учитывая, что $\delta_{\text {баз. }}=2,0$, принимаем $h_{\text {баз. }}=$ 1,8 . Рассчитывали шаги движения остальных факторов $\left(h_{i}\right)$ по формуле: $h_{i}=h_{\text {баз. }} \gamma_{i}$. Округляя значения $h_{2}, h_{3}$, имеем следующие шаги движения по градиенту: $h_{1}=1,80, h_{2}=$ $0,099, h_{3}=0,10$.

3. Рассчитывали условия и результаты опытов крутого восхождения (мысленных опытов). Значения факторов, определяющие условия опытов, определяли по формуле: $X_{j i}=X_{j-1, i}+h_{i}$, где $j-$ номер опыта, $i-$ номер фактора. Результаты мысленных опытов $\left(y_{j m}\right)$ рассчитывали по модели $Y=b_{0}+b_{1} X_{1}+b_{2} X_{2}+b_{3} X_{3}-b_{4} X_{4}=2499,9+410,9 X_{1}+$ $451,6 X_{2}+409,7 X_{3}-156,6 X_{4}$ для $X_{j i}$, вычисленных по формуле $X_{j i}=X_{j-1, i}+h_{i}$. Аналогично рассчитывали условия и результаты остальных опытов (табл. 4).

Движение по градиенту считали эффективным, если реализация мысленных опытов, рассчитанных на стадии крутого восхождения, приводила к увеличению значения параметра оптимизации (стафилолитической активности) по сравнению с наилучшим результатом в матрице полного факторного эксперимента (табл. 5).

Как видно, стафилолитическая активность штамма 2Р-15, выявленная в реализованном опыте № 2, составляет 4100,8 ед./мл. Кроме того, реализованы опыты № 3 и 5, в которых при движении по градиенту фактор $\left(X_{I}\right)$ достигал границ допустимых значений, при этом данный фактор стабилизировался и движение осуществлялось по остальным факторам $X_{2}$ и $X_{3}$ (см. табл. 4). 
Расчет крутого восхождения для определения количественного соотношения компонентов среды

\begin{tabular}{|l|c|c|c|}
\hline \multicolumn{1}{|c|}{ Характеристика фактора и опыта } & $X_{1}$ & $X_{2}$ & $X_{3}$ \\
\hline Интервал варьирования $\left(\sigma_{i}\right)$ & 2,0 & 0,1 & 0,5 \\
\hline Коэффициент регрессии $\left(b_{i}\right)$ & 410,9 & 451,6 & 409,7 \\
\hline Произведение $L_{i}=b_{i} \sigma_{i}$ & 821,80 & 45,16 & 54,85 \\
\hline Коэффициент $\left(\gamma_{i}\right)$ & 1,000 & 0,055 & 0,067 \\
\hline Шаг движения $\left(h_{i}\right)$ & 1,8 & 0,1 & 0,1 \\
\hline
\end{tabular}

Состав сред и стафилолитическая активность,

Таблица 5 выявленная в результате мысленных и реализованных опытов методом крутого восхождения

\begin{tabular}{|c|c|c|c|c|c|}
\hline № опыта & $X_{1}$, г/л & $X_{2}$, г/л & $X_{3}$, г/л & $Y_{\text {мыссл*., ед./мл }}$ & $Y_{\text {реал**, }}$ ед./мл \\
\hline 1 & 13,8 & 0,4 & 1,6 & 3403,1 & - \\
\hline 2 & 15,6 & 0,5 & 1,7 & 4306,3 & 4100,8 \\
\hline 3 & 15,6 & 0,6 & 1,8 & 4838,0 & 4932,7 \\
\hline 4 & 15,6 & 0,7 & 1,9 & 5373,1 & - \\
\hline 5 & 15,6 & 0,8 & 2,0 & 5906,5 & 5589,4 \\
\hline
\end{tabular}

Примечания: * - стафилолитическая активность ферментов, теоретически рассчитанная в программе Microsoft Excel по методу крутого восхождения, ** - стафилолитическая активность ферментов, полученная экспериментальным путем по методу крутого восхождения.

На основании проведенных исследований можно заключить, что крутое восхождение в данном случае оказалось эффективным, так как, сравнивая наилучший результат ПФЭ $2^{4}$ (3811,0 ед./мл) с полученным в реализованом опыте № 5 (5589,4 ед./мл), видим, что активность продукта увеличивается в 1,5 раза. В результате эксперимента по плану «крутого восхождения» разработана ферментационная среда следующего состава (г/л): глюкоза - 15,6, $\mathrm{K}_{2} \mathrm{HPO}_{4}-0,8, \mathrm{NH}_{4} \mathrm{NO}_{3}-2,0, \mathrm{CaCO}_{3}-4,2, \mathrm{CaCl}_{2}-2,0$, $\mathrm{MnCl}_{2}-0,015, \mathrm{FeSO}_{4}-0,05, \mathrm{ZnSO}_{4}-2,0 \cdot 10^{-4}$. На данной среде стафилолитическая активность штамма 2P-15 достигала 5589,4 ед./мл, что более чем в 1,86 раза превысило среднюю активность на исходной среде, полученной симплексным методом планирования эксперимента.

Для подтверждения достигнутых результатов проведен контрольный эксперимент на двух ферментационных средах (исходной и оптимальной), подтвердивший эффективность оптимизации на основе математического планирования эксперимента методом крутого восхождения. Неожиданным оказался такой же положительный эффект, выявленный для штамма П-29, активность которого на оптимальной для штамма 2Р-15 среде превысила контроль в 1,95 раза и составляла 3900 ед./мл.

\section{Выводы}

Коэффициенты уравнения регрессии, рассчитанные по ПФЭ $2^{4}$ для основных компонентов ферментационной среды штамма 2Р-15, оказались значимыми относительно глюкозы, двузамещенного фосфата калия и нитрата аммония. Реализация опытов, рассчитанных на стадии крутого восхождения, обеспечила увеличение значения стафилолитической активности штамма 2P-15 по сравнению с самым хорошим результатом в матрице факторного эксперимента в 1,5 раза. Крутое восхождение оказалось эффективным, так как наилучший результат стафилолитической активности для ПФЭ $2^{4}$ составил 3811 ед./мл, а в реализованом опыте № $5-5589,4$ ед./мл. Разработанная методом крутого восхождения ферментационная среда для штамма 2P-15 позволи- 
ла увеличить его стафилолитическую активность более чем в 1,9 раза по сравнению с контрольной средой, рассчитанной ранее симплексным методом.

\section{Библиографические ссылки}

1. Адлер Ю. П. Планирование эксперимента при поиске оптимальных условий / Ю. П. Адлер, Е. В. Маркова, Ю. В. Грановский. - М. : Наука, 1976. - 280 с.

2. Арзамасцев А. А. Математические модели кинетики микробного синтеза: возможности использования и новые подходы к разработке / А. А. Арзамасцев, А. А. Андреев // Вестн. Тамбов. ун-та. Серия: Естеств. и техн. науки. - 2000. - Т. 5, № 1. - С. 111-130.

3. Бирюков В. В. Оптимизация периодических процессов микробиологического синтеза / В. В. Бирюков, В. М. Кантере. - М. : Наука, 1985. - 296 с.

4. Божков А. И. Биотехнология. - Харьков : Федорко, 2008. - 364 c.

5. Гайдадин А. Н. Применение средств ЭВМ при обработке активного эксперимента / А. Н. Гайдадин, С. А. Ефремова. - Волгоград : Волг. ГТУ, 2008. - 16 с.

6. Жерносекова И. В. Изменчивость продуцента литических ферментов Streptomyces recifensis var. lyticus и его селекция: Автореф. дисс. ... канд. биол. наук. - К., 2002. - 20 с.

7. Использование метода протопластирования в селекции продуцента литических ферментов S. recifensis var. lyticus / Т. Я. Куликова, А. С. Стенько, Н. К. Безкоровайная и др. // Антибиотики и химиотер. - 1994. - Т. 39, № 2/3. - С. 9-12.

8. Математическая модель биосинтеза $L$-лейцина / Д. С. Осипов, Т. В. Гусельникова и др. // Труды МГУИЭ. - 2001. - Т. 5. - С. 19-23.

9. Монттомери Д. К. Планирование эксперимента и анализ данных. - Л. : Судостроение, 1980. $384 \mathrm{c}$.

10. Оптимизация биотехнологического процесса выращивания актиномицетов с использованием перфторуглеродов / М. К. Бакулин, А. С. Кучеренко, Н. А. Кривошеина и др. // Наука производство - технологии - экология. Сб. матер. Всеросс. научн.-техн. конф. - Киров : ЦДООШШ, 2003. - Т. 3. - С. 90-91.

11. Перт С. Д. Основы культивирования микроорганизмов и клеток. - М. : Мир, 1978. - 331 с.

12. Практикум по микробиологии / Под ред. Н. С. Егорова. - М. : МГУ, 1976. - 307 с.

13. Применение полного факторного эксперимента при проведении исследований: Метод. указания / А. Н. Гайдадин, С. А. Ефремова. - Волгоград : Волг. ГТУ, 2008. - 16 с.

14. Соколова И. Е. Выделение и изучение бактериолитического ферментного комплекса Actinomyces recifensis var. lyticus 2435: Автореф. дисс. ... канд. биол. наук. - М., 1985. - 17 c.

15. Шинкаренко Л. Н. Литические ферменты Actinomyces recifensis var. lyticus 2435 и условия, влияющие на их биосинтез: Автореф. дисс. ... канд. биол. наук. - М., 1979. - 16 с.

16. Bajpai R. K. A mechanistic model for penicillin production / R. K. Bajpai, M. Reuss // J. Chem. Technol. and Biotechnol. - 1980. - Vol. 30. - P. 332-344.

17. Ettler P. Determination of the optimal feeding regime during biosynthesis of erythromycin / P. Ettler, J. Votruba // Folia Microbiol. - 1980. - Vol. 25. - P. 424-429.

18. Isono M. Bacteriolytic enzyme and process for the production there of Pat. 3649454USA, C12 K $1 /$ 06 / M. Isono, T. Takahashi, Y. Yamadzaki. - Publ. 10.04.1972.

Надійшла до редколегї 11.08.2010 